\title{
Distribution of the ATP-binding cassette transporter ABCG8 IVS1-2A>G genotype and clinical characteristics of gallbladder patients in Northeastern Mexico: A pilot study
}

\author{
PAMELA FRIGERIO $^{1}$, ANA CECILIA CEPEDA-NIETO ${ }^{2}$, SELIM MARCOS-MORALES ${ }^{1}$, ABEL PEÑA-VELÁZQUEZ ${ }^{1}$, \\ SERGIO DÁVILA-FLORES ${ }^{3}$ and MAURICIO SALINAS-SANTANDER ${ }^{2}$ \\ ${ }^{1}$ Facultad de Medicina Unidad Saltillo, Universidad Autónoma de Coahuila, Saltillo, Coahuila 25000; \\ ${ }^{2}$ Departamento de Investigación, Facultad de Medicina Unidad Saltillo, Universidad Autónoma de Coahuila, Saltillo, \\ Coahuila 25000; ${ }^{3}$ Departamento de Cirugía, Hospital Universitario de Saltillo 'Dr. Gonzalo Valdés Valdés', \\ Universidad Autónoma de Coahuila, Saltillo, Coahuila 2500, Mexico
}

Received March 13, 2018; Accepted June 29, 2018

DOI: $10.3892 /$ br.2018.1123

\begin{abstract}
Biliary lithiasis is a multifactorial pathology determined by the interaction of genes and the environment, characterized by alterations in cholesterol homeostasis and in the metabolism of bile salts. A number of gene polymorphisms and mutations have been identified in the ATP-dependent cholesterol transporter (ABCG8) associated with lithiasis disease. The aim of the present study was to evaluate the association of the ABCG8 gene mutation IVS1-2A>G with cholecystolithiasis in patients from Northeast Mexico. This was a pilot study including 90 Mexican subjects diagnosed by ultrasonography, $57.8 \%$ of which presented gallstones. The studied parameters included: Lipid profile, total protein in plasma and polymerase chain reaction-restriction fragment length polymorphism genotyping. Significant differences were identified in total plasma protein, weight and BMI values, with these being these higher in subjects with gallstones $(\mathrm{P}<0.05)$. The presence of the mutant allele IVS1-2G was not detected, and the IVS1-2A wild-type allele was present in $100 \%$ of the population. Therefore, no association was apparent between the presence of the splice site mutation in ABCG8 (IVS1-2A>G) and the presence of gallstones in the evaluated subjects.
\end{abstract}

\section{Introduction}

Cholecystolithiasis is an established health problem with medical, social and economic implications due to its typically high rate of occurrence and associated complications. It is a

Correspondence to: Dr Mauricio Salinas-Santander, Departamento de Investigación, Facultad de Medicina Unidad Saltillo, Universidad Autónoma de Coahuila, 205 Calle Francisco Murguía Sur, Zona Centro, Saltillo, Coahuila 25000, Mexico

E-mail:msalinsa@yahoo.com

Key words: ATP-binding cassette transporter G8, IVS1-2A>G mutation, biliary lithiasis, gallstones chronic and frequent pathology of the digestive system, and is generally treated by cholecystectomy (1). Cholecystolithiasis is among the five main reasons prompting surgical intervention worldwide, and the primary reason in Mexico and other countries in Latin America (1), and thus represents the digestive disease with greatest economic burden in Western countries (2). In modern times, biliary lithiasis has been described as a multifactorial pathology, determined by the interaction of genes and the environment and characterized by alterations in cholesterol homeostasis and in the metabolism of bile salts (3). In this regard, the ATP-binding cassette gene subfamily G member 8 (ABCG8), which transports cholesterol to the canalicular membrane of hepatocytes and the brush border of enterocytes, has been described as a major genetic determinant for the development of gallstones in humans (3), and is among the most studied of ABC transporters at clinical and experimental levels (4-6).

In 2002, it was reported that Sitosterolemia may be caused by mutations in exon 5 of the ABCG8 gene (c.584T>A; Leu195Gln) in a German population (7). In fact, mutations and polymorphisms in ABCG5 and ABCG8 genes were identified in these patients (7). In other studies, the involvement of ABCG8 gene polymorphisms D19H and Y54C/T400K have been associated with the development of gallstone disease in German, Romanian, Scandinavian, Chinese and Indian populations, among others $(8,9)$. Recently, a genome-wide association study meta-analysis conducted by Joshi et al (10) revealed the association of two ABCG8 gene polymorphisms, rs11887534 and rs4245791, with the risk of developing gallstones.

Furthermore, a study conducted by Hubacek et al (11) identified an ABCG8 gene mutation in the splicing acceptor of intron 1 (IVS1-2A>G) in patients with Sitosterolemia, inducing alternative splicing. However, to the best of our knowledge there have been no new studies describing the participation of IVS1-2A $>$ G gene mutation in the development of Sitosterolemia and gallstone disease to date.

As gallstone lithiasis is a common pathology in Mexico, and there is a lack of published Mexican studies determining the existence of clinical, biochemical and molecular markers 
for prognostic utility, the present study aimed to analyze the association between altered clinical parameters, including biochemical factors, lipid profile and body mass index, and the ABCG8 gene mutation IVS1-2A>G in the development of cholecystolithiasis in patients from Northeast Mexico, in order to identify possible therapeutic targets. To this end a comparative cross-sectional in-hospital pilot study was performed.

\section{Materials and methods}

Selection of participants. A total of 90 Mexican patients recruited between January 2016 and July 2017 from the Department of Surgery of the University Hospital of Saltillo, Mexico, were organized into two groups. The first group consisted of patients presenting with cholesterol gallstones, while the second group consisted of control subjects without gallstones. Approval for the use of human subjects in clinical research was obtained in December 2015 from the Ethics Committee of the University Hospital of Saltillo. Informed consent was obtained from all included subjects following explanation of the study protocol.

The inclusion criteria for the first and second groups were as follows: Subjects of both sex and of any age who attended the University Hospital of Saltillo, with (patient group) and without (control group) diagnosis of cholelithiasis. Patients with any genetic diseases including familial hypercholesterolemia, with gallbladder cancer or with non-adequate (hemolyzed) blood samples were excluded from both groups. The patient were selected following upper abdominal ultrasonography (ACUSONX300; Siemens Medical Solutions, Erlangen, Germany). The subjects were weighed and measured for height using a BAME scale with a stadiometer (model MMBAD02; Bame Industries, Puebla, Mexico). BMI was calculated as bodyweight divided by the square of the height $\left(\mathrm{kg} / \mathrm{m}^{2}\right)$. Peripheral venous blood samples $(5 \mathrm{ml})$ were collected into two $6 \mathrm{ml}$ tubes, one without anticoagulant, which was processed for lipid profile with a Vitros 250 autoanalyzer (GMI Inc., Ramsey, MN, USA) using a ready-made dry slide chemistry kit (Lipid Panel; Johnson \& Johnson, New Brunswick, NJ, USA) and the other with EDTA anticoagulant for DNA extraction. The lipid profile assessed total cholesterol, triglycerides, high-density lipoprotein (HDL)-cholesterol, low-density lipoprotein (LDL)-cholesterol and very low-density lipoprotein (VLDL)-cholesterol. The atherogenic index of the plasma was determined as the ratio of LDL to HDL. Reference values were according those in the Guidelines of the Mexican Official Standard ('Norma Oficial Mexicana NOM-037-SSA2-2012, for the prevention, treatment and control of dyslipidemias') (12).

DNA extraction. The peripheral venous blood samples in the EDTA tubes were centrifuged at 1,800 x g for $5 \mathrm{~min}$ at room temperature, and the buffy-coat was processed for high molecular weight genomic DNA isolation with phenol-chloroform, precipitated in ethanol and suspended in Tris-EDTA (pH 7.8).

Genotyping the splice site mutation in ABCG8 (IVS1-2A>G). The ABCG8 gene was genotyped by polymerase chain reaction (PCR), followed by restriction analysis using the enzyme NlaIV (New England Biolabs, Ipswich, MA, USA) following the protocol described by Hubacek et al (11). PCR was performed using an MJ Mini PTC1148 thermal cycler (Bio-Rad Laboratories, Inc., Hercules, CA, USA) in a volume of $25 \mu \mathrm{l}$ as follows: $250 \mathrm{ng}$ genomic DNA, $0.5 \mu \mathrm{M}$ primers (forward, 5'-TGTCTTCTCCTA TGTTCTCAGCAG-3' and reverse primer, 5'-TGCTCCTCTCC CCTTGAAC-3'), $0.2 \mathrm{mM}$ dNTP's, $1.5 \mathrm{mM} \mathrm{MgCl}_{2}$ and 2.5 units Taq DNA polymerase (Promega Corporation, Madison, WI, USA). The PCR program consisted of 30 cycles at $94^{\circ} \mathrm{C}$ for $30 \mathrm{sec}$, $54^{\circ} \mathrm{C}$ for $30 \mathrm{sec}$ and $72^{\circ} \mathrm{C}$ for $30 \mathrm{sec}$.

The IVS1-2A allele results in the gain of a restriction site for the NlaIV enzyme. When the IVS1-2A allele is present, the 199 bp PCR amplicon is digested with the enzyme NlaIV, generating two fragments of 164 and 136 bp (11). The IVS1-2G allele was detected by the lack of cleavage by the NlaIV enzyme, leaving the 199 bp PCR amplicon intact.

Statistical analysis. Demographic, clinical, biochemical and molecular data was collected from the patients and organized into a database. All statistical calculations were performed using SPSS software version 17.0 for Windows (SPSS, Inc., Chicago, IL, USA). Quantitative variables were expressed as means \pm standard deviation and the qualitative values as percentages. Descriptive statistics were performed for the demographic, clinical and biochemical data of each subject. Any difference in the quantitative values obtained between clinical, biochemical and molecular parameters was determined through Student's t-test for variables with normal distribution and Mann-Whitney U test for variables with non-normal distribution. The possible association between genotype and categorical variables of biological and clinical parameters was assessed using contingency tables and $\chi^{2}$ statistics. $\mathrm{P}<0.05$ was considered to indicate statistical significance.

\section{Results}

Clinical characteristics of the participants. A total of 90 subjects were analyzed, of which 67 were women (74.4\%) and 23 were men $(25.6 \%)$. Overall $57.8 \%$ of the study subjects had gallstones [15 men (16.7\%) and 37 women (41.1\%)], leaving $42.2 \%$ without [8 men $(8.9 \%)$ and 30 women $(33.3 \%)]$.

The most frequent pathologies observed in the included subjects were diabetes mellitus type $2(8.9 \%, \mathrm{n}=8$; in 3 subjects with normal gallbladder and 5 with gallstones), systemic arterial hypertension $(4.4 \%, n=4$; in 1 subject with normal gallbladder and 3 with gallstones), and both diabetes and hypertension $(4.4 \%, n=4$; in 1 subject with normal gallbladder and 3 with gallstones).

Regarding biochemical characteristics (Table I), 73 patients (81.1\%) exhibited normal cholesterol levels (50-200 mg/dl) whereas 17 (18.9\%) exhibited high cholesterol levels $(>200 \mathrm{mg} / \mathrm{dl}$ ) and thus were hypercholesterolemic; 41 patients $(45.6 \%)$ presented normal triglyceride levels (50-150 mg/dl) while $47(52.2 \%)$ presented high levels (>150 mg/dl; hypertriglyceridemic) and 2 patients $(2.2 \%)$ exhibited values $<50 \mathrm{mg} / \mathrm{dl}$. HDL values ranged from $40-60 \mathrm{mg} / \mathrm{dl}$ in 42 patients $(46.7 \%)$ to $<40 \mathrm{mg} / \mathrm{dl}$ in 41 patients (45.6\%) and $>60 \mathrm{mg} / \mathrm{dl}$ in 7 patients $(7.8 \%)$. LDL values were optimal, between $0-130 \mathrm{mg} / \mathrm{dl}$, in 82 patients (91.1\%) and high, $>130 \mathrm{mg} / \mathrm{dl}$, in 8 patients $(8.9 \%)$. VLDL values were normal, between $2-30 \mathrm{mg} / \mathrm{dl}$, in 45 patients $(50 \%)$ and high, $>30 \mathrm{mg} / \mathrm{dl}$, in 45 patients. The atherogenic index was estimated to be 
Table I. Clinical and biochemical parameters.

\begin{tabular}{|c|c|c|c|c|c|}
\hline Clinical/biochemical parameter & Variable & Normal gallbladder $(\mathrm{n}=38)$ & Gallstones $(\mathrm{n}=52)$ & $\chi^{2}$ & P-value \\
\hline \multirow[t]{2}{*}{ Sex, n } & Male & 8 & 15 & \multirow[t]{2}{*}{0.701} & \multirow{2}{*}{0.402} \\
\hline & Female & 30 & 37 & & \\
\hline \multirow[t]{2}{*}{ Cholesterol, mg/dl } & $50-200$ & 33 & 40 & \multirow[t]{2}{*}{1.410} & \multirow{2}{*}{0.235} \\
\hline & $>200$ & 5 & 12 & & \\
\hline \multirow[t]{2}{*}{ Low-density lipoprotein, mg/dl } & $0-130$ & 36 & 46 & \multirow[t]{2}{*}{0.433} & \multirow{2}{*}{0.510} \\
\hline & $>130$ & 2 & 6 & & \\
\hline \multirow[t]{2}{*}{ Very low-density lipoprotein, mg/dl } & $2-30$ & 20 & 25 & \multirow[t]{2}{*}{0.182} & \multirow[t]{2}{*}{0.670} \\
\hline & $>30$ & 18 & 27 & & \\
\hline \multirow[t]{3}{*}{ Triglycerides, mg/dl } & $<50$ & 2 & 0 & \multirow[t]{3}{*}{2.809} & \multirow[t]{3}{*}{0.246} \\
\hline & $50-150$ & 17 & 24 & & \\
\hline & $>150$ & 19 & 28 & & \\
\hline \multirow[t]{3}{*}{ High-density lipoprotein, mg/dl } & $<40$ & 14 & 27 & \multirow[t]{3}{*}{3.408} & \multirow[t]{3}{*}{0.182} \\
\hline & $40-60$ & 22 & 20 & & \\
\hline & $>60$ & 2 & 5 & & \\
\hline \multirow[t]{3}{*}{ Atherogenic index } & $<0.7$ & 1 & 3 & \multirow[t]{3}{*}{0.560} & \multirow[t]{3}{*}{0.756} \\
\hline & $0.7-3.9$ & 35 & 46 & & \\
\hline & $>3.9$ & 2 & 3 & & \\
\hline
\end{tabular}

Table II. Clinical and biochemical parameters associated with gallstones.

\begin{tabular}{lcrc}
\hline $\begin{array}{l}\text { Clinical/biochemical } \\
\text { parameter }\end{array}$ & $\begin{array}{c}\text { Normal } \\
\text { gallbladder } \\
(\mathrm{n}=38)\end{array}$ & \multicolumn{1}{c}{$\begin{array}{c}\text { Gallstones } \\
(\mathrm{n}=52)\end{array}$} & P-value \\
\hline Cholesterol, mg/dl & $159.5 \pm 46.8$ & $166.9 \pm 51.3$ & 0.482 \\
Triglycerides, mg/dl & $163.7 \pm 81.0$ & $174.1 \pm 98.2$ & 0.597 \\
HDL, mg/dl & $42.2 \pm 14.6$ & $44.2 \pm 17.9$ & 0.560 \\
LDL, mg/dl & $86.2 \pm 34.4$ & $87.1 \pm 39.4$ & 0.910 \\
VLDL, mg/dl & $32.7 \pm 16.2$ & $34.8 \pm 19.7$ & 0.584 \\
Atherogenic index & $2.21 \pm 0.89$ & $2.14 \pm 1.00$ & 0.722 \\
Total plasma & $6.23 \pm 1.25$ & $6.75 \pm 0.97$ & 0.028 \\
protein, mg/dl & & & \\
Weight, $\mathrm{kg}$ & $72.4 \pm 13.9$ & $78.3 \pm 14.3$ & 0.022 \\
Height, $\mathrm{m}$ & $1.64 \pm 0.08$ & $1.64 \pm 0.08$ & 0.755 \\
Body mass & $27.1 \pm 5.74$ & $29.0 \pm 5.29$ & 0.038 \\
index, $\mathrm{kg} / \mathrm{m}^{2}$ & & & \\
\hline
\end{tabular}

Data shown are the mean \pm standard deviation.

$0.7-3.9 \mathrm{mg} / \mathrm{dl}$ in 81 patients $(90.0 \%),>3.9 \mathrm{mg} / \mathrm{dl}$ in 5 patients $(5.6 \%)$ and $<0.7 \mathrm{mg} / \mathrm{dl}$ in 4 patients $(4.4 \%)$.

Concerning the group of 52 patients with cholecystolithiasis, 12 (23.1\%) exhibited hypercholesterolemia, 28 (53.8\%) exhibited hypertriglyceridemia, 27 (51.9\%) exhibited low HDL, 27 (51.9\%) exhibited elevated VLDL and 6 (11.5\%) exhibited elevated LDL levels. In the control group, hypercholesterolemia was determined in $5(13.2 \%)$ of 38 subjects, as well as hypertriglyceridemia in 16 (50.0\%), low HDL levels in $14(36.8 \%)$, elevated VLDL in $18(47.4 \%)$ and elevated LDL in $2(5.3 \%)$ of these subjects.

Regarding the distribution of biochemical parameters, sex and diagnosis of gallstones, no significant differences were identified between the groups (Table I).

When comparing the mean values for the clinical and biochemical variables considered, a significant difference between the normal gallbladder and gallstone groups was identified in total protein in plasma $(6.23 \pm 1.25$ vs. $6.75 \pm 0.97 \mathrm{mg} / \mathrm{dl}$; $\mathrm{P}=0.028)$, weight $(72.4 \pm 13.9$ vs. $78.3 \pm 14.3 \mathrm{~kg} ; \mathrm{P}=0.022)$ and BMI (27.1 \pm 5.74 vs. $29.0 \pm 5.29 ; \mathrm{P}=0.038)$; these parameters were significantly higher in the group with gallstones (Table II).

Allele and genotype analysis. The analysis by PCR-restriction fragment length polymorphism assay revealed that the wild-type allele A (IVS1-2A) was present in $100 \%$ of the population (IVS1-2A/IVS1-2A genotype), whereas the variant allele G (IVS1-2G) was absent. For this reason, a causal relationship between the frequency of the mutation and the clinical and biochemical data could not be determined.

\section{Discussion}

Gallstones are a condition occurring globally though exhibits a variable prevalence according to the demographics of the analyzed population. A prevalence of $20.0 \%$ has been reported in the United Kingdom (13), whereas in Mexican-American women a prevalence of $26.7 \%$ has been reported (14). Regarding the latter, however, necropsy studies performed in Mexico have reported a lower prevalence of $14 \%$, with a higher prevalence in females (20.4\%) than in males (8.5\%) (15). Meanwhile, indigenous populations from Chile and Peru appear highly susceptible to lithiasis, presenting a nearly $100 \%$ risk of disease development in the female population (13). These studies are 
in accord with results in the present study, where gallstone prevalence $(57.8 \%$ overall) was higher in women $(41.1 \%)$ than in men $(16.7 \%)$.

The present study aimed to analyze the association between the ABCG8 gene mutation IVS1-2A>G and cholelithiasis, mainly because this gene mutation has been previously implicated with an increased hepatic secretion of cholesterol and consequent predisposition to gallstones (11).

Studies in mice have revealed that the stimulation of ABCG8 by Niemann-Pick C2, a cholesterol-binding protein secreted by the biliary system, resulted in the positive regulation of biliary cholesterol secretion (16). A study of more than 500,000 genotyped single nucleotide polymorphisms suggested that the His19 variant of the ABCG8 gene could be associated with more efficient cholesterol transport into bile (17). Meanwhile, a study conducted in mice revealed that the ABCG5/G8-independent pathway serves an important role in the regulation of biliary cholesterol secretion, in the transport of HDL-derived cholesterol from plasma to bile, and in gallstone formation, separate from the ABCG5/G8 pathway (18). A previous meta-analysis demonstrated a marked association between the $\mathrm{D} 19 \mathrm{H}$ polymorphism and gallstone disease. In this same study, the T400K and Y54C polymorphisms also appeared associated with gallstone disease, though to a lesser extent $(9,19)$.

Although association of the ABCG8 gene mutation with an increased risk of developing gallstones has been reported previously (7), the present study identified no apparent association between the IVS1-2A $>$ G mutation with the development of gallstones in a Mexican population; since $100 \%$ of the analyzed population presented the wild-type allele A (IVS1-2A). However, it is noteworthy that the sample size was small $(n=90)$, and thus potentially compromised the conclusions drawn from this study, since a sample size of at least 196 subjects would be required for a sufficient statistical power ( $\mathrm{n}$ of Saltillo population $=807,537$, prevalence of 15 and $95 \%$ confidence level); nevertheless, this was enough to reflect the genotypic distribution of the splice site mutation in ABCG8 (IVS1-2A $>$ G) in the study population.

The presence of gallstones in the analyzed population was significantly associated with higher values of total protein in plasma $(6.75 \mathrm{~g} / \mathrm{dl} ; \mathrm{P}=0.028)$, as well as with higher weight (78.3 kg; $\mathrm{P}=0.022)$ and BMI $\left(29.0 \mathrm{~kg} / \mathrm{m}^{2} ; \mathrm{P}=0.038\right)$ when compared with the subjects without gallstones. Regarding total protein in plasma, it is noteworthy that the average protein value determined in patients with and without gallstones was within the normal range (6.5-8.1 g/dl) (20); however, the difference in values between the groups was identified to be significant and therefore associated with the presence of gallstones. These results have not been reported previously in similar studies.

Concerning weight and BMI, previous study has not established a direct correlation between overweight or obese phenotype and the development of symptomatic cholelithiasis, mainly because it is also observed in subjects with normal BMI (21); regardless, the risk of symptomatic cholelithiasis appears to increase with higher BMI (21). This association was also apparent in the present study, where BMI within the overweight range $\left(25-30 \mathrm{~kg} / \mathrm{m}^{2}\right)(22)$ was associated with the presence of gallstones. Furthermore, there may be a direct correlation between increased percentage of general and abdominal fat and increased risk of developing gallbladder disease, with previous studies indicating an almost two-fold increased risk even within the range of normal BMI (23).

Other clinical and biochemical variables analyzed in this study, including cholesterol, Triglycerides, HDL, LDL and VLDL levels, atherogenic index, height and sex, were not determined as significant risk factors for the development of gallstones in the analyzed population.

In conclusion, no association was apparent between the presence of the splice site mutation in ABCG8 (IVS1-2A>G) and the presence of gallstones in the evaluated subjects. However, alterations were observed in the level of total protein, weight and BMI, which were significantly higher in the subjects presenting with gallstones.

\section{Acknowledgements}

The authors would like to thank Dr Daniel Diaz, former researcher at the Department of Clinical Biochemistry of the University Hospital of Charles University, Hradec Kralove, Czech Republic, for his assistance in proofreading the manuscript.

\section{Funding}

The present study was funded by the Research Department of the Facultad de Medicina Unidad Saltillo and the Hospital Universitario de Saltillo 'Dr. Gonzalo Valdes', Universidad Autónoma de Coahuila, Saltillo, Mexico.

\section{Availability of data and materials}

The datasets used and/or analyzed during the present study are available from the corresponding author on reasonable request.

\section{Authors' contributions}

PF, SMM, SDF and MSS conceived the study. PF, ACCN, SMM, MSS and APV designed the study. PF and SMM were responsible for patient enrollment. PF, SMM and MSS performed the data analyses. PF, SMM, and MSS interpreted the data. PF, SMM, ACCN, MSS, APV drafted the manuscript. PF, SMM, ACCN, MSS and APV critically revised the manuscript. All authors read and approved the final manuscript.

\section{Ethics approval and consent to participate}

The Institutional Review Board of the Hospital Universitario de Saltillo, Saltillo, Coahuila, Mexico, approved and registered the study, December 2015. Informed consent for participation was obtained from all included subjects following explanation of the study protocol.

\section{Consent for publication}

All included subjects provided written informed consent allowing the publication of relevant data on the terms of data anonymization. 


\section{Competing interests}

The authors declare that they have no competing interests.

\section{References}

1. Almora Carbonell CL, Arteaga Prado Y, Plaza González T, Prieto Ferro Y and Hernández Hernández: Diagnóstico clínico y epidemiológico de la litiasis vesicular. Revisiónbibliográfica. Rev Cienc Méd 16: 200-214, 2012.

2. Venneman NG and van Erpecum KJ.: Pathogenesis of gallstones. Gastroenterol Clin North Am 39: 171-183, 2010.

3. Lammert F, Gurusamy K, Ko CW, Miquel JF, Mendez-Sanchez N, Portincasa P, van Erpecum KJ, van Laarhoven CJ and Wang DQ: Gallstones. Nat Rev Dis Primers 2: 16024, 2016.

4. Grünhage F, Acalovschi M, Tirziu S, Walier M, Wienker TF, Ciocan A, Mosteanu O, Sauerbruch T and Lammert F: Increased gallstone risk in humans conferred by common variant of hepatic ATP-binding cassette transporter for cholesterol. Hepatology 46: 793-801, 2007.

5. Cuperus FJ, Claudel T, Gautherot J, Halilbasic E and Trauner M: The role of canalicular ABC transporters in cholestasis. Drug Metab Dispos 42: 546-560, 2014.

6. Yoo EG: Sitosterolemia: A review and update of pathophysiology, clinical spectrum, diagnosis, and management. Ann Pediatr Endocrinol Metab 21: 7-14, 2016.

7. Heimerl S, Langmann T, Moehle C, Mauerer R, Dean M, Beil FU, von Bergmann K and Schmitz G: Mutations in the human ATP-binding cassette transporters ABCG5 and ABCG8 in sitosterolemia. Hum Mutat 20: 151-155, 2002.

8. Renner O, Lütjohann D, Richter D, Strohmeyer A, Schimmel S, Müller O, Stange EF and Harsch S: Role of the ABCG8 19H risk allele in cholesterol absorption and gallstone disease. BMC Gastroenterol 13: 30, 2013.

9. Jiang ZY, Cai Q and Chen EZ: Association of three common single nucleotide polymorphisms of ATP binding cassette G8 gene with gallstone disease: A meta-analysis. PLoS One 9: e87200, 2014.

10. Joshi AD, Andersson C, Buch S, Stender S, Noordam R, Weng LC, Weeke PE, Auer PL, Boehm B, Chen C, et al: Four susceptibility loci for gallstone disease identified in a meta-analysis of genome-wide association studies. Gastroenterology 151: 351-363. e28, 2016.

11. Hubacek JA, Berge KE, Cohen JC and Hobbs HH: Mutations in ATP-cassette binding proteins G5 (ABCG5) and G8 (ABCG8) causing sitosterolemia. Hum Mutat 18: 359-360, 2001.
12. De la Federación, D.O.: NOM-037-SSA2-2012, para la prevención, tratamiento y control de las dislipidemias. Mexico: Diario Oficial de la Federación: 1-38, 2012.

13. Johnson CD: ABC of the upper gastrointestinal tract. Upper abdominal pain: Gall bladder. BMJ 323: 1170-1173, 2001.

14. Everhart JE, Khare M, Hill M and Maurer KR: Prevalence and ethnic differences in gallbladder disease in the United States. Gastroenterology 117: 632-639.1999.

15. Méndez-Sánchez N, Jessurun J, Ponciano-Rodríguez G, Alonso-de-Ruiz P, Uribe M and Hernández-Avila M: Prevalence of gallstone disease in Mexico. A necropsy study. Dig Dis Sci 38: 680-683, 1993.

16. Yamanashi Y, Takada T, Yoshikado T, Shoda J and Suzuki H: NPC2 regulates biliary cholesterol secretion via stimulation of ABCG5/G8-mediated cholesterol transport. Gastroenterology 140: 1664-1674, 2011.

17. Buch S, Schafmayer C, Völzke H, Becker C, Franke A, von Eller-Eberstein H, Kluck C, Bässmann I, Brosch M, Lammert F, et al: A genome-wide association scan identifies the hepatic cholesterol transporter ABCG8 as a susceptibility factor for human gallstone disease. Nat Genet 39: 995-999, 2007.

18. Wang HH, Li X, Patel SB and Wang DQ: Evidence that the adenosine triphosphate-binding cassette G5/G8-independent pathway plays a determinant role in cholesterol gallstone formation in mice. Hepatology 64: 853-864, 2016.

19. von Kampen O, Buch S, Nothnagel M, Azocar L, Molina H, Brosch M, Erhart W, von Schönfels W, Egberts J, Seeger M, et al: Genetic and functional identification of the likely causative variant for cholesterol gallstone disease at the ABCG5/8 lithogenic locus. Hepatology 57: 2407-2417, 2013.

20. Olay G, Díaz P, Hernández R, Cervantes-Villagrana RD, Presno-Bernal J and Alcántara L: Determinación de intervalos de referencia para química clínica en población mexicana. Rev Latinoamer Patol Clin 60: 43-51, 2013.

21. Kharga B, Sharma BK, Singh VK, Nishant K, Bhutia P, Tamang R and Jain N: Obesity not necessary, risk of symptomatic cholelithiasis increases as a function of BMI. J Clin Diagn Res 10: PC28-PC32, 2016.

22. World Health Organization Obesity: Preventing and Managing the Global Epidemic. Report of a WHO Consultation on Obesity. World Health Organization, Geneva, 1998.

23. Aune D, Norat T and Vatten LJ: Body mass index, abdominal fatness and the risk of gallbladder disease. Eur J Epidemiol 30: 1009-1019, 2015. 